Supporting Information for ...

\title{
O2 Protonation Controls Threshold Behavior for N-Glycosidic Bond Cleavage of Protonated Cytosine Nucleosides
}

\author{
R. R. Wu and M. T. Rodgers* \\ Department of Chemistry, Wayne State University, Detroit, Michigan, 48202, United States
}

Experimental Procedures. Cross sections for collision-induced dissociation (CID) of $[\mathrm{dCyd}+\mathrm{H}]^{+}$and $[\mathrm{Cyd}+\mathrm{H}]^{+}$are measured using a custom-built guided ion beam tandem mass spectrometer that has previously been described in detail. ${ }^{1}$ The protonated nucleosides are generated using a custom-built electrospray ionization (ESI) source $^{2,3}$ from solutions of $0.1 \mathrm{mM}$ nucleoside and $1 \mathrm{mM}$ hydrochloric acid $(\mathrm{HCl})$ in a mixture of 50\%:50\% $\mathrm{MeOH} / \mathrm{H}_{2} \mathrm{O}$. Droplets emanating from the 35 gauge stainless steel ESI needle are introduced into the vacuum region through capillary tubing, biased at $20-50 \mathrm{~V}$, and heated to $100-120^{\circ} \mathrm{C}$. The ions are focused and thermalized in an rf ion funnel ${ }^{4,5}$ and hexapole ion guide collision cell interface. The thermalized ions are extracted from the hexapole ion guide, accelerated and focused into a magnetic sector momentum analyzer for selection of the precursor ion, $[\mathrm{dCyd}+\mathrm{H}]^{+}$or $[\mathrm{Cyd}+\mathrm{H}]^{+}$. The mass-selected ions are decelerated to a desired kinetic energy using an exponential retarder and focused into an octopole ion guide that traps the ions in the radial direction. ${ }^{6}$ The octopole passes through a static gas cell containing Xe as the collision gas. The pressure of Xe is kept low ( $\sim 0.05-0.20$ mTorr) enough to ensure that multiple ion-neutral collisions are improbable. The reasons for choosing Xe as the collision gas have been described elsewhere. ${ }^{7-9}$ Product and undissociated precursor ions drift to the end of the octopole where they are guided and focused into a quadrupole mass filter for the second stage of mass analysis. The ions are detected using a secondary electron scintillation (Daly) detector and standard pulse counting techniques. ${ }^{10}$

Theoretical Calculations. N3 and $\mathrm{O} 2$ protonated conformers of $[\mathrm{dCyd}+\mathrm{H}]^{+}$and $[\mathrm{Cyd}+\mathrm{H}]^{+}$coexist in the gas phase and thus both are examined as stable reactants. ${ }^{11}$ The Gaussian 09 suite of programs ${ }^{12}$ are used to perform relaxed PES scans for both $\mathrm{N} 3$ and $\mathrm{O} 2$ protonated conformers to generate initial guesses for the transition states (TSs) for N-glycosidic bond cleavage at the B3LYP/6-31G(d) level of theory. Transition state calculations (TS, QST2 and QST3) ${ }^{13,14}$ are performed at the B3LYP/6-311+G(d,p) level of theory to optimize structures of the relevant TSs. Intrinsic reaction coordinate (IRC) calculations at the same level of theory are performed to confirm that the optimized TS structures connect the correct relevant species along the dissociation pathways. Vibrational analyses of the geometry-optimized structures are performed to determine the vibrational frequencies of the optimized structures for use in modeling of the CID data. The frequencies calculated were scaled by a factor of 0.99. ${ }^{15}$ The scaled vibrational frequencies and rotational constants are listed in Tables S1-S4 of the Supporting Information. Single point energy calculations are performed at the B3LYP/6-311+G(2d,2p) and the MP2(full)/6$311+\mathrm{G}(2 \mathrm{~d}, 2 \mathrm{p})$ levels of theory for all species computed. To obtain accurate energetics, zero point energy (ZPE) corrections are included. Basis set superposition error (BSSE) corrections ${ }^{16,17}$ are also included for the dissociation products. 
Data Handling. Ion intensities are converted to absolute cross sections as described previously using a Beer's law analysis. ${ }^{18}$ Due to the errors in the pressure measurement and uncertainties in the length of the interaction region, uncertainties in the cross-section magnitudes are approximately $\pm 20 \%$, whereas the relative uncertainties are approximately $\pm 5 \%$.

Ion kinetic energies in the laboratory frame are converted to energies in the center-of-mass frame, $E_{\mathrm{CM}}$, using the formula, $E_{\mathrm{CM}}=E_{\text {lab }} m /(m+M)$, where $M$ and $m$ are the masses of the ionic, $[\mathrm{dCyd}+\mathrm{H}]^{+}$and $[\mathrm{Cyd}+\mathrm{H}]^{+}$, and neutral Xe reactants, respectively. The absolute zero and distribution of the ion kinetic energies are determined using the octopole ion guide as a retarding potential analyzer as previously described. ${ }^{18}$ The distribution of ion kinetic energies is nearly Gaussian with a full width at half-maximum (fwhm) between 0.2 and $0.5 \mathrm{eV}$ (lab) for these experiments. The uncertainty in the absolute energy scale is $\pm 0.05 \mathrm{eV}$ (lab).

The effects of multiple collisions can significantly influence the shape of CID cross sections ${ }^{19}$ even when the pressure of $\mathrm{Xe}$ is low. Pressure-dependent studies of all cross sections have been measured. Cross sections are extrapolated to zero pressure ${ }^{19}$ of the Xe reactant to provide data that are rigorously the result of single collision conditions, and thus provide reliable thermochemistry.

Thermochemical Analysis. The threshold regions of the measured CID cross sections of the two primary CID pathways involving glycosidic bond cleavage are modeled competitively using the empirical threshold law of eq S1,

$$
\sigma_{j}(E)=\frac{n \sigma_{0, j}}{E} \sum_{i} g_{i} \int_{0}^{E+E_{i}-E_{0}} \frac{k_{j}\left(E^{*}\right)}{k_{t o t}\left(E^{*}\right)}\left[1-e^{-k_{t o t}\left(E^{*}\right) \tau}\right](\Delta E)^{n-1} d(\Delta E)
$$

where $\sigma_{0}$ is an energy independent scaling factor, $E$ is the relative translational energy of the reactants, $E_{0}$ is the threshold for reaction of the ground electronic and ro-vibrational state, $E_{i}$ is the excitation energy of each state, and $n$ is an adjustable parameter that describes the efficiency of kinetic to internal energy transfer. ${ }^{20} \tau$ is the experimental time available for dissociation, and $k$ is the unimolecular dissociation rate constant. $\Delta E$ is the energy that remains in translation after collision between the reactants. $E^{*}=E+E_{i}-\Delta E$ is the internal energy of the energized molecule after the collision. The indices $j$ refer to the individual dissociation channels (reactions 1 and 2), where $k_{j}$ is the unimolecular rate constant for dissociation channel $j\left(\Sigma k_{j}=k_{t o t}\right.$ ). The scaling factors, $\sigma_{0, j}$, are ideally the same for all product channels. However, independent scaling was required to reproduce the data with high fidelity. The summation is over the ro-vibrational states of the reactant ions, $[\mathrm{dCyd}+\mathrm{H}]^{+}$and $[\mathrm{Cyd}+\mathrm{H}]^{+}$, where $g_{i}$ is the population of those state $\left(\sum g_{i}=1\right)$. Because $[\mathrm{dCyd}+\mathrm{H}]^{+}$and $[\mathrm{Cyd}+\mathrm{H}]^{+}$possess many low-frequency vibrational modes, the populations of excited vibrational modes are not negligible at $298 \mathrm{~K}$. Thus, the internal energy of the reactant ion contributes significantly to the reaction threshold (See Tables S1 and S2 of the Supporting Information). Whether the dissociation of $[\mathrm{dCyd}+\mathrm{H}]^{+}$and $[\mathrm{Cyd}+\mathrm{H}]^{+}$occurs within the time scale of the experiments, $\sim 10^{-4} \mathrm{~s}$, must be taken into account in the thermochemical analysis procedures to ensure extraction of accurate energetics. Therefore, RiceRamsperger-Kassel-Marcus (RRKM) theory was included as described in detail elsewhere. ${ }^{21,22}$ Sets of ro-vibrational frequencies appropriate for the energized reactants and the transition states (TSs) leading to dissociation are required to properly analyze the threshold energies. For the activated dissociation processes studied here, the tight transition 
states (TTSs) associated with the pathways for N-glycosidic bond cleavage are explicitly modeled theoretically to determine appropriate molecular parameters for the thermochemical analysis of the experimental data. Before comparison to the experimental data, eq $\mathrm{S} 1$ is convoluted with the kinetic energy distributions of the $[\mathrm{dCyd}+\mathrm{H}]^{+}$or $[\mathrm{Cyd}+\mathrm{H}]^{+}$and Xe reactants, and a nonlinear least-squares analysis of the data is performed to give optimized values for the parameters, $\sigma_{0}, E_{0}$, and $n$.

In this work, the observed $\mathrm{N}$-glycosidic bond cleavage reactions leading to production of the protonated nucleobase, $[\mathrm{Cyt}+\mathrm{H}]^{+}$, from $[\mathrm{dCyd}+\mathrm{H}]^{+}$and $[\mathrm{Cyd}+\mathrm{H}]^{+}$are activated dissociation processes, which involve TTSs. Based on the theoretically predicted PESs, two TTSs, $\mathrm{TS}_{1}$ associated with glycosidic bond elongation and $\mathrm{TS}_{2}$ associated with transfer of $\mathrm{C}^{\prime}-\mathrm{H}$, must be overcome. The energies of $\mathrm{TS}_{1}$ and $\mathrm{TS}_{2}$ are quite close and both exceed the final reaction enthalpy (including BSSE corrections). In particular, for production of $[\mathrm{Cyt}+\mathrm{H}]^{+}$from $[\mathrm{dCyd}+\mathrm{H}]^{+}$ and $[\mathrm{Cyd}+\mathrm{H}]^{+}$, B3LYP finds $\mathrm{TS}_{1}$ as the rate-determining step, whereas MP2 suggests that $\mathrm{TS}_{2}$ is the ratedetermining step. The molecular parameters of both $\mathrm{TS}_{1}$ and $\mathrm{TS}_{2}$ leading to the production of $[\mathrm{Cyt}+\mathrm{H}]^{+}$from $[\mathrm{dCyd}+\mathrm{H}]^{+}$and $[\mathrm{Cyd}+\mathrm{H}]^{+}$are therefore used for data analysis. For the elimination of the neutral nucleobase, Cyt, producing $[\mathrm{Nuo}-\mathrm{Cyt}+\mathrm{H}]^{+}$, theory predicts a TS also involving glycosidic bond elongation, $\mathrm{TS}_{\mathrm{n}}$, that differs from $\mathrm{TS}_{1}$. $\mathrm{TS}_{\mathrm{n}}$ lies more than $50 \mathrm{~kJ} / \mathrm{mol}$ lower in energy than the dissociation asymptote (including BSSE corrections). For CID processes corresponding to activate bond cleavage reactions where TSs and intermediates along the reaction pathways lie well below the dissociation asymptote, we assume that the TSs are loose and product-like such that the TS vibrations used for analysis are the frequencies corresponding to the dissociation products. The transitional frequencies, those that become rotations of the completely dissociated products, are treated as rotors corresponding to a phase space limit (PSL) model as described in detail elsewhere. ${ }^{21}$ Similar behavior is predicted by theory for elimination of Gua from $[\mathrm{dGuo}+\mathrm{H}]^{+}$and $[\mathrm{Guo}+\mathrm{H}]^{+}$. We have determined that a switching (SW) TS model (including $\mathrm{TS}_{\mathrm{n}}$ and PSL) is the most appropriate for analysis of this dissociation channel. ${ }^{11}$ Previous studies ${ }^{23-31}$ have also verified the efficacy in modeling reactions that compete through loose as well as loose vs TTSs. Competitive analysis of the thresholds for the two primary CID pathways involving N-glycosidic bond cleavage in this work thus employ a TTS and a SW TS (TS 1 or $\mathrm{TS}_{2}$ and $\left.\mathrm{TS}_{\mathrm{n}}+\mathrm{PSL}\right)$ model for reactions (1) and (2).

The density of ro-vibrational states ${ }^{32-34}$ is evaluated using the Beyer-Swinehart algorithm and the relative populations, $g_{i}$, are calculated for a Maxwell-Boltzmann distribution at $298 \mathrm{~K}$, the internal temperature of the $[\mathrm{dCyd}+\mathrm{H}]^{+}$and $[\mathrm{Cyd}+\mathrm{H}]^{+}$reactants. The vibrational frequencies, average internal energies and rotational constants at $298 \mathrm{~K}$, of the reactant ions, $[\mathrm{dCyd}+\mathrm{H}]^{+}$and $[\mathrm{Cyd}+\mathrm{H}]^{+}$, TSs, and dissociation products are given in Tables S1-S4. The errors in the measured thresholds are estimated from the range of values determined for the zero-pressureextrapolated data sets, variations associated with uncertainties in the vibrational frequencies (prescaled by 0.99 ), \pm $10 \%$, and the error in the absolute energy scale, $\pm 0.05 \mathrm{eV}$ (lab). For analyses that include the RRKM lifetime analysis, the uncertainties in the measured thresholds also include the effects of increasing and decreasing the time assumed available for dissociation by a factor of 2 .

Conversion from 0 to $298 \mathrm{~K}$. To allow comparison to commonly employed experimental conditions, we convert the $0 \mathrm{~K}$ AEs and $\Delta \mathrm{H}_{\mathrm{rxn}} \mathrm{s}$ determined from the threshold analyses to $298 \mathrm{~K}$ enthalpies and free energies based on the $\mathrm{O} 2$ protonated reactants. The enthalpy and entropy conversions are calculated using standard formulas (assuming harmonic oscillator and rigid rotor models) and vibrational and rotational constants determined for the 
B3LYP/6-311+G(d,p) optimized geometries, which are given in Tables S1 and S3 of the Supporting Information. Table S12 lists 0 and $298 \mathrm{~K}$ enthalpies, free energies, and enthalpic and entropic corrections for both $[\mathrm{dCyd}+\mathrm{H}]^{+}$and $[\mathrm{Cyd}+\mathrm{H}]^{+}$experimentally determined. Enthalpic and entropic corrections are determined by $\pm 10 \%$ variation in all vibrationl frequencies, and additionally by $\pm 50 \%$ variation in the frequencies below $300 \mathrm{~cm}^{-1}$.

N-Glycosidic Bond Cleavage of $[\mathbf{d C y d}+\mathbf{H}]^{+}$and $[\mathbf{C y d}+\mathbf{H}]^{+}$. As can be seen in Figure 3a, production of $[\mathrm{Cyt}+\mathrm{H}]^{+}$is a multistep process. In the ground-state $\mathrm{O} 2$ protonated conformer of $[\mathrm{dCyd}+\mathrm{H}]^{+}$, the glycosidic bond is $1.506 \AA$ long. In the first step, the glycosidic bond elongates to $3.482 \AA$, and the $\mathrm{O} 2$ protonated cytosine residue approaches the $\mathrm{C} 2^{\prime}-\mathrm{H}$ atom, leading to the first $\mathrm{TS}, \mathrm{TS}_{1}$, where the distance between N1 and H2' is $2.281 \AA$. The relative energy difference between ground-state $[\mathrm{dCyd}+\mathrm{H}]^{+}$and $\mathrm{TS}_{1}$ determines the first activation barrier. The $\mathrm{O} 2$ protonated cytosine residue approaches $\mathrm{C}^{\prime}-\mathrm{H}$ more closely and forms a $\mathrm{N} 1 \cdots \mathrm{H}-\mathrm{C} 2$ ' noncanonical hydrogen bonding interaction, stabilizing the structure and leading to a stable oxacarbenium-type charged sugar intermediate. In $\mathrm{TS}_{2}, \mathrm{C}^{2}$-H starts to transfer from the sugar to N1, forming a proton-bound dimer between the nucleobase and the sugar. The relative energy difference between $[\mathrm{dCyd}+\mathrm{H}]^{+}$and $\mathrm{TS}_{2}$ determines the second activation barrier. After $\mathrm{C} 2$ '-H transfers to $\mathrm{N} 1$ forming protonated cytosine, the electron density of the $\mathrm{C} 2$ '-H bond rehybridizes to form a double bond forms between $\mathrm{C} 1^{\prime}$ and $\mathrm{C}^{\prime}, \mathrm{C}^{\prime}=\mathrm{C} 2^{\prime}=1.340 \AA$, leading to a planar neutral sugar. The $\mathrm{O} 2$ protonated cytosine and neutral planar sugar are stabilized by $\mathrm{N} 1-\mathrm{H}^{\cdots} \mathrm{C} 2$ ' and $\mathrm{C} 6-\mathrm{H} \cdots \mathrm{O} 5$ ' pseudo hydrogen-bonding interactions, forming the final stable intermediate. Dissociation of these noncovalent interactions leads to smooth dissociation into the final products, protonated cytosine, $[\mathrm{Cyt}+\mathrm{H}]^{+}$, and the neutral 2'-deoxyribose sugar moiety, [Nuo-Cyt]. B3LYP predicts that $\mathrm{TS}_{1}$ lies $2.1 \mathrm{~kJ} / \mathrm{mol}$ higher in energy than $\mathrm{TS}_{2}$. In contrast, MP2 predicts that $\mathrm{TS}_{1}$ is $1.3 \mathrm{~kJ} / \mathrm{mol}$ lower in energy than $\mathrm{TS}_{2}$. Both levels of theory predict that these two activation barriers exceed the final reaction enthalpy. Therefore, either $\mathrm{TS}_{1}$ or $\mathrm{TS}_{2}$ may be the rate-limiting $\mathrm{TS}$ for this dissociation pathway. Shown in Figure $3 \mathrm{~b}$ is the calculated PES for glycosidic bond cleavage resulting in elimination of neutral Cyt from $[\mathrm{dCyd}+\mathrm{H}]^{+}$. As can be seen, the glycosidic bond gradually elongates to $2.913 \AA$. The orientation and the relative position of the nucleobase to the sugar of $\mathrm{TS}_{\mathrm{n}}$ differ markedly from those of $\mathrm{TS}_{1}$. After the nucleobase departs the sugar, a pseudo hydrogen-bonding interaction between $\mathrm{N} 1$ and $\mathrm{H} 1$ ' is formed, leading to a stable oxacarbenium-ion intermediate. Cleavage of the $\mathrm{C} 1{ }^{\prime}-\mathrm{H} \cdots \mathrm{N} 1$ noncovalent interaction leads to smooth dissociation into the products, a positively charged nonplanar 2'-deoxyribose sugar moiety, $[\mathrm{Nuo}-\mathrm{Cyt}+\mathrm{H}]^{+}$, and a noncanonical tautomer of neutral cytosine. The dissociation asymptote is the rate-limiting step for this dissociation pathway as it lies more than $50 \mathrm{~kJ} / \mathrm{mol}$ higher in energy than $\mathrm{TS}_{\mathrm{n}}$. The calculated PESs for producing $[\mathrm{Cyt}+\mathrm{H}]^{+}$and $[\mathrm{Cyd}-\mathrm{Cyt}+\mathrm{H}]^{+}$from $[\mathrm{Cyd}+\mathrm{H}]^{+}$are shown in Figure 4. The dissociation mechanisms are very parallel to those for $[\mathrm{dCyd}+\mathrm{H}]^{+}$. Similarly, B3LYP finds $\mathrm{TS}_{1}$ to be the rate-limiting step, whereas MP2 finds $\mathrm{TS}_{2}$ to be the rate-limiting step for N-glycosidic bond cleavage to produce $[\mathrm{Cyt}+\mathrm{H}]^{+}$from $[\mathrm{Cyd}+\mathrm{H}]^{+}$. The dissociation products are again rate-limiting for producing $[\mathrm{Cyd}-\mathrm{Cyt}+\mathrm{H}]^{+}$ as they lie more than $50 \mathrm{~kJ} / \mathrm{mol}$ above $\mathrm{TS}_{\mathrm{n}}$, and thus are modeled in the same fashion as $[\mathrm{dCyd}+\mathrm{H}]^{+}$. 


\section{References}

(1) Rodgers, M. T. J. Phys. Chem. A 2001, 105, 2374-2383.

(2) Chen, Y.; Rodgers, M. T. J. Am. Chem. Soc. 2012, 134, 2313-2324.

(3) Moison, R. M.; Armentrout, P. B. J. Am. Soc. Mass Spectrom. 2007, 18, 1124-1134.

(4) Shaffer, S. A.; Prior, D. C.; Anderson, G. A.; Udseth, H. R.; Smith, R. D. Anal. Chem. 1998, 70, 4111-4119.

(5) Shaffer, S. A.; Tolmachev, A.; Prior, D. C.; Anderson, G. A.; Udseth, H. R.; Smith, R. D. Anal. Chem. 1999, 71, 2957-2964.

(6) Teloy, E.; Gerlich, D. Chem. Phys. 1974, 4, 417-427.

(7) Dalleska, N. F.; Honma, K.; Armentrout, P. B. J. Am. Chem. Soc. 1993, 115, 12125-12131.

(8) Aristov, N.; Armentrout, P. B. J. Phys. Chem. 1986, 90, 5135-5140.

(9) Hales, D. A.; Armentrout, P. B. J. Cluster Sci. 1990, 1, 127-142.

(10) Daly, N. R.; Rev. Sci. Instrum. 1959, 31, 264-267.

(11) Wu, R. R.; Chen, Y.; Rodgers, M. T. Phys. Chem. Chem. Phys. 2016, 18, 2968-2980.

(12) Frisch, M. J.; et al. Gaussian 09, Revision C.01; Gaussian, Inc.: Wallingford, CT, 2009. See Supporting Information for full reference.

(13) Peng, C.; Schlegel, H. B. Israel J. Chem. 1993, 33, 449-454.

(14) Peng, C.; Ayala, P. Y.; Schlegel, H. B.; Frisch, M. J. J. Comp. Chem. 1996, 17, 49-56.

(15) Montgomery, J. A., Jr.; Frisch, M. J.; Ochterski, J. W.; Petersson, G. A. J. Chem. Phys. 1999, 110, 2822-2827.

(16) Boys, S. F.; Bernardi, R. Mol. Phys. 1979, 19, 553-566.

(17) van Duijneveldt, F. B.; van Duijneveldt-van de Rijdt, J. G. C. M.; van Lenthe, J. H. Chem, Rev. 1994, 94, $1873-$ 1885.

(18) Ervin, K. M.; Armentrout, P. B. J. Chem. Phys. 1985, 83, 166-189.

(19) Dalleska, N. F.; Honma, K.; Sunderlin, L. S.; Armentrout, P. B. J. Am. Chem. Soc. 1994, 116, 3519-3528.

(20) Muntean, F.; Armentrout, P. B. J. Chem. Phys. 2001, 115, 1213-1228.

(21) Rodgers, M. T.; Ervin, K. M.; Armentrout, P. B. J. Chem. Phys. 1997, 106, 4499-4508.

(22) Khan, F. A.; Clemmer, D. E.; Schultz, R. H.; Armentrout, P. B. J. Phys. Chem. 1993, 97, 7978-7987.

(23) Yang, B.; Wu, R. R.; Rodgers, M. T. Anal. Chem. 2013, 85, 11000-11006.

(24) Muntean, F.; Armentrout, P. B. J. Phys. Chem. B 2002, 106, 8117-8124.

(25) Muntean, F.; Heumann, L.; Armentrout, P. B. J. Chem. Phys. 2002, 116, 5593-5602.

(26) Narancic, S. Bach, A.; Chen, P. J. Phys. Chem. A 2007, 111, 7006-7013.

(27) Jia, B.; Angel, L. A.; Ervin, K. M. J. Phys. Chem. A 2008, 112, 1773-1782.

(28) Ruan, C.; Rodgers, M. T. J. Am. Chem. Soc. 2009, 131, 10918-10928.

(29) Chen, Yu.; Rodgers, M. T. J. Am. Chem. Soc. 2012, 134, 2313-2324.

(30) Chen, Yu.; Rodgers, M. T. J. Am. Chem. Soc. 2012, 134, 5863-5875.

(31) Chen, Yu.; Rodgers, M. T. Anal. Chem. 2012, 84, 7570-7577.

(32) Beyer, T. S.; Swinehart, D. F. Commun. ACM 1973, 16, 379-379.

(33) Stein, S. E.; Rabinovitch, B. S. J. Chem. Phys. 1973, 58, 2438-2445.

(34) Stein, S. E.; Rabinovitch, B. S. Chem. Phys. Lett. 1977, 49, 183-188.

Ref. 43 [complete reference]: Gaussian 09, Revision A.1, Frisch, M. J.; Trucks, G. W.; Schlegel, H. B.; Scuseria, G. E.; Robb, M. A.; Cheeseman, J. R.; Scalmani, G.; Barone, V.; Mennucci, B.; Petersson, G. A.; Nakatsuji, H.; Caricato, M.; Li, X.; Hratchian, H. P.; Izmaylov, A. F.; Bloino, J.; Zheng, G.; Sonnenberg, J. L.; Hada, M.; Ehara, M.; Toyota, K.; Fukuda, R.; Hasegawa, J.; Ishida, M.; Nakajima, T.; Honda, Y.; Kitao, O.; Nakai, H.; Vreven, T.; Montgomery, Jr., J. A.; Peralta, J. E.; Ogliaro, F.; Bearpark, M.; Heyd, J. J.; Brothers, E.; Kudin, K. N.; Staroverov, V. N.; Kobayashi, R.; Normand, J.; Raghavachari, K.; Rendell, A.; Burant, J. C.; Iyengar, S. S.; Tomasi, J.; Cossi, M.; Rega, N.; Millam, J. M.; Klene, M.; Knox, J. E.; Cross, J. B.; Bakken, V.; Adamo, C.; Jaramillo, J.; Gomperts, R.; Stratmann, R. E.; Yazyev, O.; Austin, A. J.; Cammi, R.; Pomelli, C.; Ochterski, J. W.; Martin, R. L.; Morokuma, K.; Zakrzewski, V. G.; Voth, G. A.; Salvador, P.; Dannenberg, J. J.; Dapprich, S.; Daniels, A. D.; Farkas, Ö.; Foresman, J. B.; Ortiz, J. V.; Cioslowski, J.; Fox, D. J. Gaussian, Inc., Wallingford CT, 2009. 
Table S1. Vibrational Frequencies and Average Internal Energies of Ground-State Reactants, Transition States, and Products Associated with N-Glycosidic Bond Cleavage of O2 Protonated [dCyd+H $]^{+}$and $[\mathrm{Cyd}+\mathrm{H}]^{+}$.

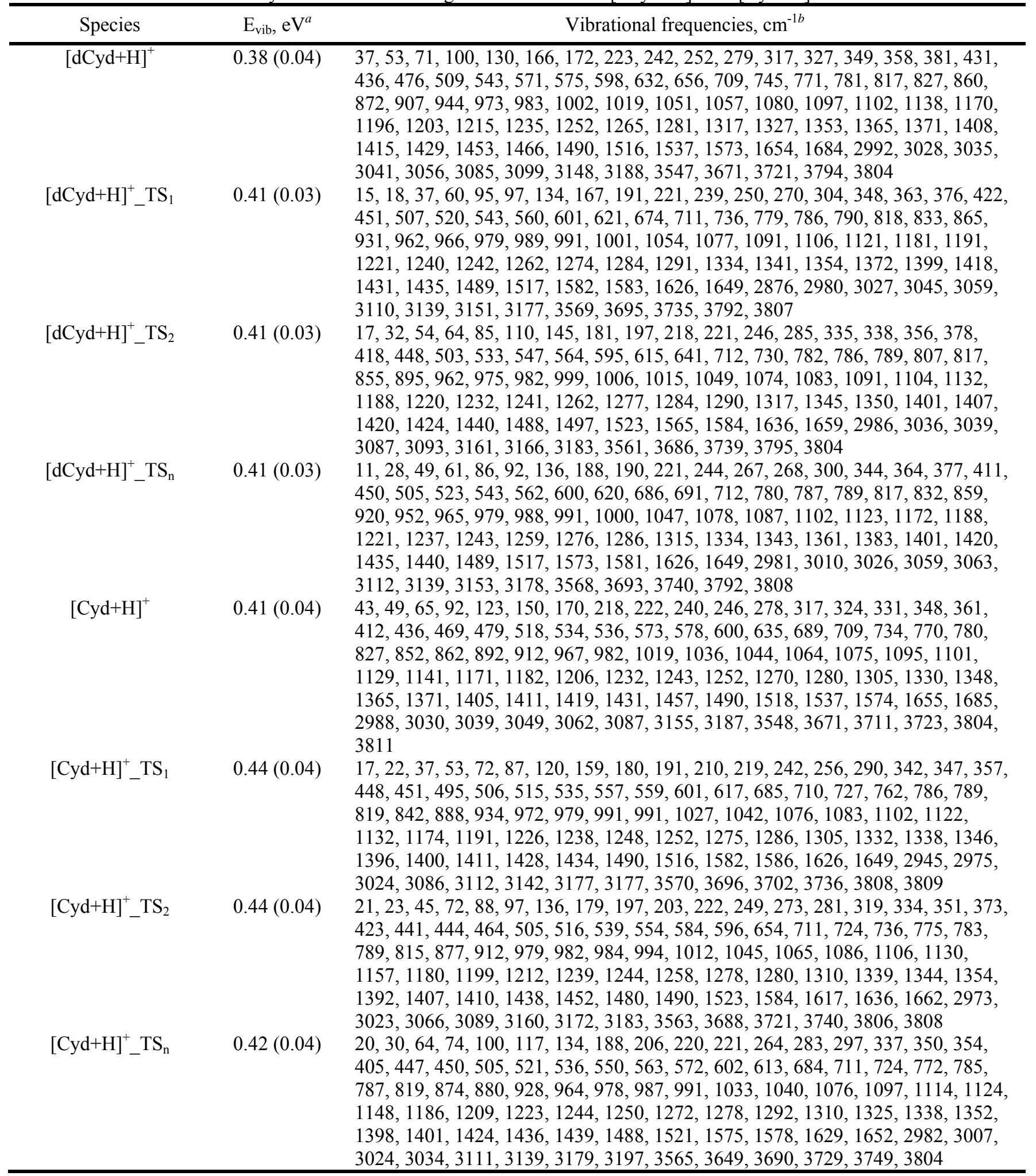


Table S1. (cont'd.) Vibrational Frequencies and Average Internal Energies of Ground-State Reactants, Transition States, and Products Associated with N-Glycosidic Bond Cleavage of O2 Protonated $[\mathrm{dCyd}+\mathrm{H}]^{+}$and $[\mathrm{Cyd}+\mathrm{H}]^{+}$.

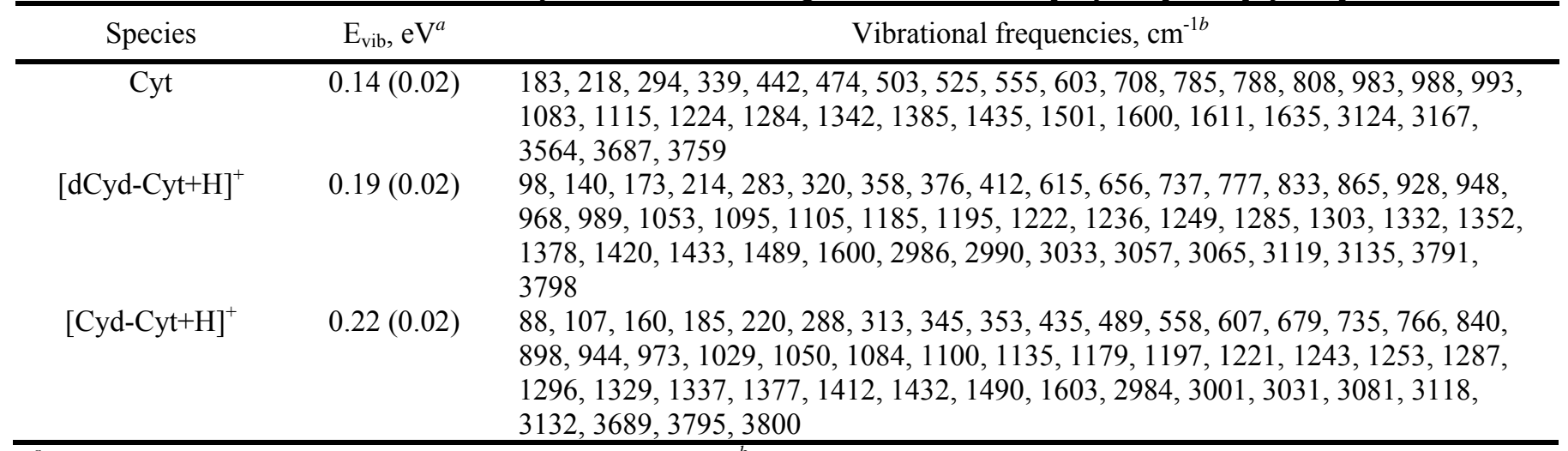

${ }^{a}$ Present results, uncertainties are listed in parentheses. ${ }^{b}$ Vibrational frequencies scaled by 0.99 obtained from vibrational analysis of the geometry optimized structures determined at the B3LYP/6-311+G(d,p) level of theory.

Table S2. Vibrational Frequencies and Average Internal Energies of Ground-State Reactants, Transition States, and Products Associated with N-Glycosidic Bond Cleavage of N3 Protonated $[\mathrm{dCyd}+\mathrm{H}]^{+}$and $[\mathrm{Cyd}+\mathrm{H}]^{+}$.

\begin{tabular}{|c|c|c|}
\hline Species & $\mathrm{E}_{\mathrm{vib}}, \mathrm{eV}^{a}$ & Vibrational frequencies, $\mathrm{cm}^{-1 b}$ \\
\hline$[\mathrm{dCyd}+\mathrm{H}]^{+}$ & $0.38(0.04)$ & $\begin{array}{l}32,54,70,99,130,152,168,181,241,252,282,319,328,352,357,380,390, \\
423,462,469,521,563,596,640,653,656,699,746,756,778,791,816,860, \\
873,908,946,974,997,1004,1025,1055,1058,1081,1091,1105,1108,1173, \\
1189,1196,1204,1214,1256,1272,1303,1317,1328,1353,1368,1373,1400, \\
1414,1428,1448,1466,1491,1546,1591,1641,1675,1812,2992,3023,3035, \\
3040,3054,3076,3097,3133,3203,3530,3548,3659,3791,3805\end{array}$ \\
\hline$[\mathrm{dCyd}+\mathrm{H}]_{-}^{+} \mathrm{TS}_{2}$ & $0.41(0.03)$ & $\begin{array}{l}21,28,56,66,86,117,140,158,185,202,225,253,263,298,330,353,376, \\
388,419,441,530,549,588,592,636,646,697,729,764,772,775,790,805, \\
853,901,952,965,987,994,1007,1019,1048,1064,1070,1086,1104,1125, \\
1164,1183,1223,1254,1268,1278,1283,1306,1327,1343,1350,1378,1408, \\
1416,1439,1465,1489,1517,1561,1602,1616,1665,1763,2982,3030,3034, \\
3089,3105,3142,3181,3198,3535,3560,3673,3793,3809\end{array}$ \\
\hline$[\mathrm{dCyd}+\mathrm{H}]_{-}^{+} \mathrm{TS}_{\mathrm{n}}$ & $0.41(0.03)$ & $\begin{array}{l}25,28,60,68,81,123,131,160,183,192,202,248,260,301,357,367,380, \\
409,412,435,526,549,601,622,641,695,697,766,772,781,787,798,832, \\
875,942,943,964,983,993,1004,1014,1059,1062,1098,1103,1117,1169, \\
1184,1210,1224,1247,1258,1287,1320,1325,1336,1348,1370,1391,1409, \\
1421,1437,1489,1494,1575,1598,1613,1660,1699,2911,2981,3012,3027, \\
3058,3067,3109,3117,3194,3540,3569,3683,3793,3809\end{array}$ \\
\hline$[\mathrm{Cyd}+\mathrm{H}]^{+}$ & $0.41(0.04)$ & $\begin{array}{l}44,49,65,92,124,144,167,169,215,230,244,274,313,327,329,347,359, \\
393,412,456,470,472,524,539,567,599,638,653,689,698,735,754,775, \\
790,855,863,894,912,967,996,1030,1037,1046,1064,1074,1093,1096, \\
1116,1130,1165,1183,1192,1207,1243,1254,1275,1297,1309,1330,1350, \\
1367,1374,1403,1407,1418,1431,1450,1489,1547,1592,1643,1676,1821, \\
2988,3031,3036,3046,3057,3077,3131,3203,3531,3548,3659,3716,3804, \\
3812\end{array}$ \\
\hline$[\mathrm{Cyd}+\mathrm{H}]_{-}^{+} \mathrm{TS}_{2}$ & $0.43(0.04)$ & $\begin{array}{l}32,35,65,93,105,122,139,164,189,205,218,231,265,281,331,340,361, \\
386,394,428,447,447,544,550,562,595,651,656,697,712,722,758,776, \\
781,789,796,879,906,968,983,991,1002,1018,1049,1066,1074,1112, \\
1133,1156,1185,1200,1213,1234,1250,1275,1290,1318,1321,1330,1350, \\
1355,1400,1408,1439,1446,1482,1489,1526,1589,1602,1621,1669,1743, \\
2989,3011,3032,3084,3156,3165,3199,3467,3531,3556,3669,3741,3798\end{array}$ \\
\hline
\end{tabular}


Table S2. Vibrational Frequencies and Average Internal Energies of Ground-State Reactants, Transition States, and Products Associated with N-Glycosidic Bond Cleavage of N3 Protonated [dCyd $+\mathrm{H}]^{+}$and $[\mathrm{Cyd}+\mathrm{H}]^{+}$.

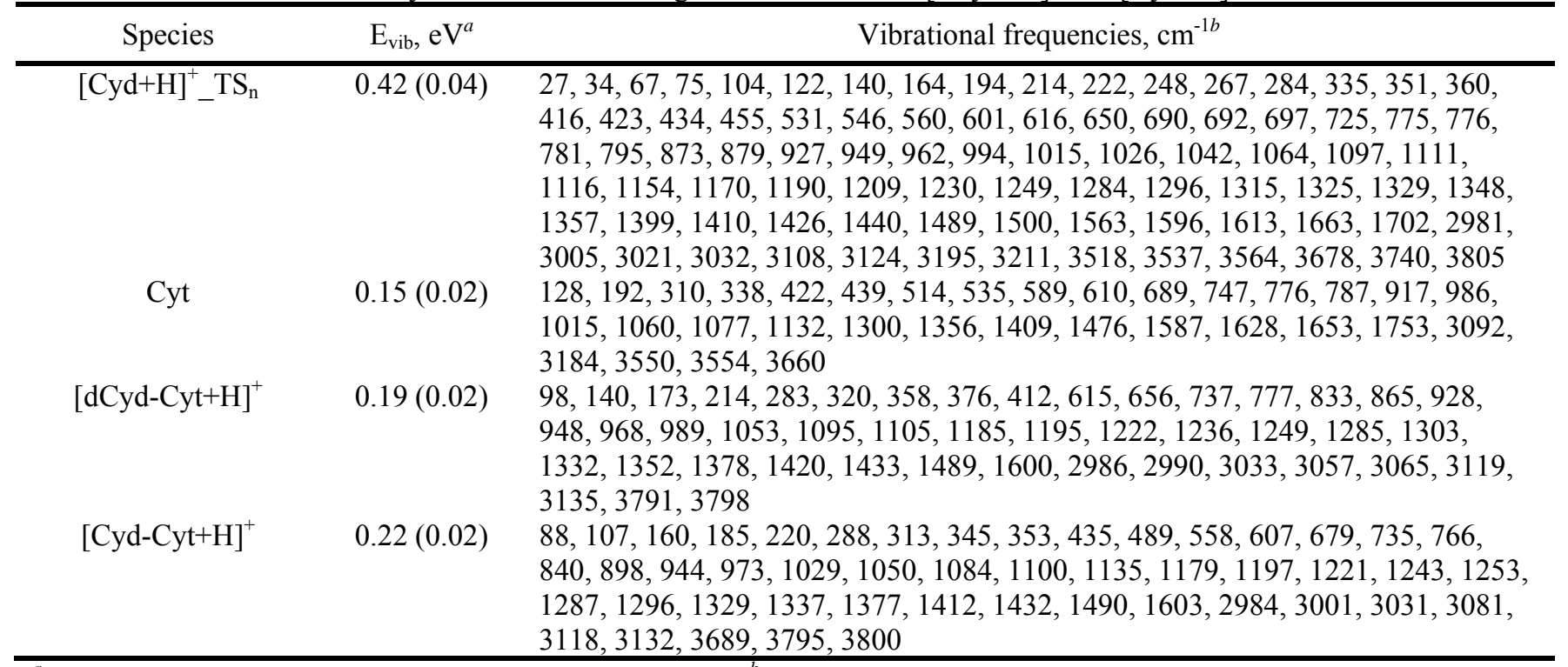

${ }^{a}$ Present results, uncertainties are listed in parentheses. ${ }^{b}$ Vibrational frequencies scaled by 0.99 obtained from vibrational analysis of the geometry optimized structures determined at the B3LYP/6-311+G(d,p) level of theory.

Table S3. Rotational Constants of O2 Protonated $[\mathrm{dCyd}+\mathrm{H}]^{+}$and $[\mathrm{Cyd}+\mathrm{H}]^{+}$and the Corresponding Tight and PSL Transition States for N-Glycosidic Bond Cleavage.

\begin{tabular}{|c|c|c|c|c|c|c|c|}
\hline \multirow{2}{*}{ Reactant } & \multirow{2}{*}{ Ionic Product } & \multicolumn{3}{|c|}{ Energized Molecule } & \multicolumn{3}{|c|}{ Transition State } \\
\hline & & $1-\mathrm{D}^{a}$ & $2-\mathrm{D}^{b}$ & & $1-\mathrm{D}^{c}$ & $2-\mathrm{D}^{c}$ & $2-\mathrm{D}^{d}$ \\
\hline \multirow[t]{4}{*}[\mathrm{dCyd}+\mathrm{H}]{$^{+}$} & {$[\mathrm{Cyt}+\mathrm{H}]^{+}$} & 0.035 & 0.010 & $\mathrm{TS}_{1}$ & 0.038 & 0.0069 & - \\
\hline & & & & $\mathrm{TS}_{2}$ & 0.033 & 0.0082 & - \\
\hline & {$[\mathrm{dCyd}-\mathrm{Cyt}+\mathrm{H}]^{+}$} & 0.035 & 0.010 & $\mathrm{TS}_{\mathrm{n}}$ & 0.039 & 0.0072 & - \\
\hline & & & & PSL & $0.10,0.13$ & $0.058,0.055$ & 0.0015 \\
\hline \multirow[t]{4}{*}[\mathrm{Cyd}+\mathrm{H}]{$^{+}$} & {$[\mathrm{Cyt}+\mathrm{H}]^{+}$} & 0.028 & 0.0096 & $\mathrm{TS}_{1}$ & 0.032 & 0.0071 & - \\
\hline & & & & $\mathrm{TS}_{2}$ & 0.029 & 0.0083 & - \\
\hline & {$[\mathrm{Cyd}-\mathrm{Cyt}+\mathrm{H}]^{+}$} & 0.028 & 0.0096 & $\mathrm{TS}_{\mathrm{n}}$ & 0.031 & 0.0073 & - \\
\hline & & & & PSL & $0.085,0.13$ & $0.043,0.055$ & 0.0015 \\
\hline
\end{tabular}
${ }^{a}$ Active external. ${ }^{b}$ Inactive external. ${ }^{c}$ Rotational constants of the transition state treated as free internal rotors. ${ }^{d}$ Two-
dimensional rotational constant of the transition state at threshold, treated variantionally and statistically.

Table S4. Rotational Constants of N3 Protonated $[\mathrm{dCyd}+\mathrm{H}]^{+}$and $[\mathrm{Cyd}+\mathrm{H}]^{+}$and the Corresponding Tight and PSL Transition States for N-Glycosidic Bond Cleavage.

\begin{tabular}{|c|c|c|c|c|c|c|c|}
\hline \multirow{2}{*}{ Reactant } & \multirow{2}{*}{ Ionic Product } & \multicolumn{3}{|c|}{ Energized Molecule } & \multicolumn{3}{|c|}{ Transition State } \\
\hline & & $\overline{1-D^{a}}$ & $2-\mathrm{D}^{b}$ & & $\overline{1-\mathrm{D}^{c}}$ & $2-\mathrm{D}^{c}$ & $2-\mathrm{D}^{d}$ \\
\hline \multirow[t]{3}{*}{$\overline{[\mathrm{dCyd}+\mathrm{H}]^{+}}$} & {$[\mathrm{Cyt}+\mathrm{H}]^{+}$} & 0.035 & 0.0099 & $\mathrm{TS}_{2}$ & 0.035 & 0.0084 & - \\
\hline & {$[\mathrm{dCyd}-\mathrm{Cyt}+\mathrm{H}]^{+}$} & 0.035 & 0.0099 & $\mathrm{TS}_{\mathrm{n}}$ & 0.040 & 0.0068 & - \\
\hline & & & & PSL & $0.10,0.13$ & $0.058,0.054$ & 0.0015 \\
\hline \multirow[t]{3}{*}[\mathrm{Cyd}+\mathrm{H}]{$^{+}$} & {$[\mathrm{Cyt}+\mathrm{H}]^{+}$} & 0.028 & 0.0095 & $\mathrm{TS}_{2}$ & 0.028 & 0.0083 & - \\
\hline & {$[\mathrm{Cyd}-\mathrm{Cyt}+\mathrm{H}]^{+}$} & & & $\mathrm{TS}_{\mathrm{n}}$ & 0.031 & 0.0074 & - \\
\hline & & & & PSL & $0.085,0.13$ & $0.043,0.054$ & 0.0015 \\
\hline
\end{tabular}

\footnotetext{
${ }^{a}$ Active external. ${ }^{b}$ Inactive external. ${ }^{c}$ Rotational constants of the transition state treated as free internal rotors. ${ }^{d}$ Twodimensional rotational constant of the transition state at threshold, treated variantionally and statistically.
} 
Table S5. Fragments Derived from Sequential Dissociation of [dCyd-Cyt $+\mathrm{H}]^{+}$and $[\mathrm{Cyd}-\mathrm{Cyt}+\mathrm{H}]^{+}$.

\begin{tabular}{ccccc}
\hline & $\mathrm{m} / \mathrm{z}$ & Chemical Formula & Symbol $^{a}$ & Neutral Losses $^{b}$ \\
\hline$[\mathrm{dCyd}-\mathrm{Cyt}+\mathrm{H}]^{+}$ & 81 & $\mathrm{C}_{5} \mathrm{H}_{5} \mathrm{O}^{+}$ & $\diamond$ & $2 \mathrm{H}_{2} \mathrm{O}$ \\
$\mathrm{m} / \mathrm{z}=117$ & 67 & $\mathrm{C}_{4} \mathrm{H}_{3} \mathrm{O}^{+}$ & $\Delta$ & $\mathrm{H}_{2} \mathrm{O}, \mathrm{CH}_{4} \mathrm{O}$ \\
$\mathrm{C}_{5} \mathrm{H}_{9} \mathrm{O}_{3}^{+}$ & 55 & $\mathrm{C}_{3} \mathrm{H}_{3} \mathrm{O}^{+}$ & $\circ$ & $2 \mathrm{H}_{2} \mathrm{O}, \mathrm{C}_{2} \mathrm{H}_{2}$ \\
& 41 & $\mathrm{C}_{2} \mathrm{HO}^{+}$ & $\square$ & $\mathrm{H}_{2} \mathrm{O}, \mathrm{CH}_{4} \mathrm{O}, \mathrm{C}_{2} \mathrm{H}_{2}$ \\
& & & & \\
{$[\mathrm{Cyd}-\mathrm{Cyt}+\mathrm{H}]^{+}$} & 83 & $\mathrm{C}_{4} \mathrm{H}_{3} \mathrm{O}_{2}{ }^{+}$ & $\Delta$ & $\mathrm{H}_{2} \mathrm{O}, \mathrm{CH}_{4} \mathrm{O}$ \\
$\mathrm{m} / \mathrm{z}=133$ & 71 & $\mathrm{C}_{3} \mathrm{H}_{3} \mathrm{O}_{2}^{+}$ & $\circ$ & $2 \mathrm{H}_{2} \mathrm{O}, \mathrm{C}_{2} \mathrm{H}_{2}$ \\
$\mathrm{C}_{5} \mathrm{H}_{9} \mathrm{O}_{4}^{+}$ & 53 & $\mathrm{C}_{3} \mathrm{HO}^{+}$ & $\square$ & $\mathrm{H}_{2} \mathrm{O}, \mathrm{CH}_{4} \mathrm{O}, \mathrm{CH}_{2} \mathrm{O}$ \\
& 41 & $\mathrm{C}_{2} \mathrm{HO}^{+}$ & $\nabla$ & $2 \mathrm{H}_{2} \mathrm{O}, \mathrm{C}_{2} \mathrm{H}_{2}, \mathrm{CH}_{2} \mathrm{O}$ \\
\hline
\end{tabular}

${ }^{a}$ Symbol designations correspond to the CID product cross sections shown in Figure 2. ${ }^{b}$ Proposed sequential neutral losses from the primary $[\mathrm{dCyd}-\mathrm{Cyt}+\mathrm{H}]^{+}$and $[\mathrm{Cyd}-\mathrm{Cyt}+\mathrm{H}]^{+} \mathrm{CID}$ products.

Table S6. Relative Energies $(\mathrm{kJ} / \mathrm{mol})$ of the Reactants, Transition States, Intermediates and Products Along the PESs for N-Glycosidic Bond Cleavage Reactions of O2 Protonated $[\mathrm{dCyd}+\mathrm{H}]^{+}$and $[\mathrm{Cyd}+\mathrm{H}]^{+}$.

\begin{tabular}{|c|c|c|c|c|c|c|c|}
\hline \multirow{2}{*}{ CID Channel } & & \multicolumn{2}{|c|}{ Relative Energies $^{a}$} & \multirow{2}{*}{ CID Channel } & & \multicolumn{2}{|c|}{ Relative Energies $^{a}$} \\
\hline & & B3LYP & MP2 & & & B3LYP & MP2 \\
\hline \multirow{6}{*}{$\begin{array}{c}{[\mathrm{Cyt}+\mathrm{H}]^{+} \text {from }} \\
{[\mathrm{dCyd}+\mathrm{H}]^{+}}\end{array}$} & $\mathrm{TS}_{1}$ & 83.8 & 121.9 & \multirow[t]{6}{*}{$\overline{[\mathrm{dCyd}-\mathrm{Cyt}+\mathrm{H}]}$} & $\mathrm{TS}_{\mathrm{n}}$ & 79.1 & 117.9 \\
\hline & $\mathrm{Int}_{1}$ & 81.0 & 121.8 & & $\operatorname{Int}_{\mathrm{n}}$ & 73.3 & 113.0 \\
\hline & $\mathrm{TS}_{2}$ & 81.7 & 123.2 & & $\Delta \mathrm{H}_{\mathrm{rxn}}$ & 153.1 & 204.7 \\
\hline & $\mathrm{Int}_{2}$ & 37.1 & 74.6 & & $\Delta \mathrm{H}_{\mathrm{rxn}}{ }^{b}$ & 147.5 & 169.3 \\
\hline & $\Delta \mathrm{H}_{\mathrm{rxn}}$ & 87.2 & 145.5 & & & & \\
\hline & $\Delta \mathrm{H}_{\mathrm{rxn}}{ }^{b}$ & 80.7 & 99.4 & & & & \\
\hline \multirow{6}{*}{$\begin{array}{c}{[\mathrm{Cyt}+\mathrm{H}]^{+} \text {from }} \\
{[\mathrm{Cyd}+\mathrm{H}]^{+}}\end{array}$} & $\mathrm{TS}_{1}$ & 111.3 & 147.3 & \multirow[t]{6}{*}[\mathrm{Cyd}-\mathrm{Cyt}+\mathrm{H}]{$^{+}$} & $\mathrm{TS}_{\mathrm{n}}$ & 90.7 & 124.0 \\
\hline & $\mathrm{Int}_{1}$ & 108.0 & 146.8 & & $\mathrm{Int}_{\mathrm{n}}$ & 88.6 & 122.5 \\
\hline & $\mathrm{TS}_{2}$ & 108.4 & 148.4 & & $\Delta \mathrm{H}_{\mathrm{rx}}$ & 177.2 & 231.5 \\
\hline & $\mathrm{Int}_{2}$ & 22.1 & 59.1 & & $\Delta \mathrm{H}_{\mathrm{rxn}} b$ & 171.2 & 194.2 \\
\hline & $\Delta \mathrm{H}_{\mathrm{rx}}$ & 81.7 & 146.2 & & & & \\
\hline & $\Delta \mathrm{H}_{\mathrm{rxn}}{ }^{b}$ & 74.5 & 97.2 & & & & \\
\hline
\end{tabular}

${ }^{a} \mathrm{~B} 3 \mathrm{LYP} / 6-311+\mathrm{G}(2 \mathrm{~d}, 2 \mathrm{p})$ and $\mathrm{MP} 2 / 6-311+\mathrm{G}(2 \mathrm{~d}, 2 \mathrm{p})$ relative energies of B3LYP/6-311+G(d,p) optimized structures at $0 \mathrm{~K}$ including $\mathrm{ZPE}$ corrections. ${ }^{b} \mathrm{BSSE}$ corrections for the final reaction products included. 
Table S7. Relative Energies $(\mathrm{kJ} / \mathrm{mol})$ of the Reactants, Transition States, Intermediates and Products Along the PESs for N-Glycosidic Bond Cleavage Reactions of N3 Protonated $[\mathrm{dCyd}+\mathrm{H}]^{+}$and $[\mathrm{Cyd}+\mathrm{H}]^{+}$.

\begin{tabular}{|c|c|c|c|c|c|c|c|}
\hline \multirow{2}{*}{ CID Channel } & & \multicolumn{2}{|c|}{ Relative Energies ${ }^{a}$} & \multirow{2}{*}{ CID Channel } & & \multicolumn{2}{|c|}{ Relative Energies $^{a}$} \\
\hline & & B3LYP & MP2 & & & B3LYP & MP2 \\
\hline \multirow{6}{*}{$\begin{array}{c}\mathrm{Cyt}+\mathrm{H}]^{+} \text {from } \\
{[\mathrm{dCyd}+\mathrm{H}]^{+}}\end{array}$} & $\overline{\mathrm{TS}_{1}}$ & 78.1 & 122.2 & \multirow[t]{6}{*}[\mathrm{dCyd}-\mathrm{Cyt}+\mathrm{H}]{$^{+}$} & \multirow{6}{*}{$\begin{array}{l}\mathrm{TS}_{\mathrm{n}} \\
\mathrm{Int}_{\mathrm{n}} \\
\Delta \mathrm{H}_{\mathrm{rxn}}{ }{ }{ }^{2} \\
\Delta \mathrm{H}_{\mathrm{rxn}}{ }^{2}\end{array}$} & 73.7 & 117.2 \\
\hline & Int $_{1}$ & 51.8 & 73.8 & & & 72.1 & 116.5 \\
\hline & $\mathrm{TS}_{2}$ & 85.9 & 125.8 & & & 179.1 & 233.6 \\
\hline & $\mathrm{Int}_{2}$ & 40.9 & 77.6 & & & 173.4 & 198.6 \\
\hline & $\Delta \mathrm{H}_{\mathrm{rxn}}$ & 91.5 & 147.0 & & & & \\
\hline & $\Delta \mathrm{H}_{\mathrm{rxn}} b$ & 85.2 & 101.6 & & & & \\
\hline \multirow{6}{*}{$\begin{array}{c}{[\mathrm{Cyt}+\mathrm{H}]^{+} \text {from }} \\
{[\mathrm{Cyd}+\mathrm{H}]^{+}}\end{array}$} & $\mathrm{TS}_{1}$ & 74.3 & 120.7 & \multirow[t]{6}{*}[\mathrm{Cyd}-\mathrm{Cyt}+\mathrm{H}]{$^{+}$} & \multirow{6}{*}{$\begin{array}{l}\mathrm{TS}_{\mathrm{n}} \\
\mathrm{Int}_{\mathrm{n}} \\
\Delta \mathrm{H}_{\mathrm{rxn}}{ }_{b}{ }{ }^{2} \mathrm{H}_{\mathrm{rxn}}\end{array}$} & 77.6 & 116.1 \\
\hline & $\mathrm{Int}_{1}$ & 73.0 & 120.0 & & & 73.1 & 115.5 \\
\hline & $\mathrm{TS}_{2}$ & 91.4 & 134.5 & & & 200.7 & 259.2 \\
\hline & $\mathrm{Int}_{2}$ & 37.3 & 68.9 & & & 194.6 & 221.9 \\
\hline & $\Delta \mathrm{H}_{\mathrm{rxn}}$ & 97.6 & 159.2 & & & & \\
\hline & $\Delta \mathrm{H}_{\mathrm{rxn}}{ }^{b}$ & 90.6 & 110.2 & & & & \\
\hline
\end{tabular}

${ }^{a} \mathrm{~B} 3 \mathrm{LYP} / 6-311+\mathrm{G}(2 \mathrm{~d}, 2 \mathrm{p})$ and $\mathrm{MP} 2 / 6-311+\mathrm{G}(2 \mathrm{~d}, 2 \mathrm{p})$ relative energies of $\mathrm{B} 3 \mathrm{LYP} / 6-311+\mathrm{G}(\mathrm{d}, \mathrm{p})$ optimized structures at $0 \mathrm{~K}$ including ZPE corrections. ${ }^{b} \mathrm{BSSE}$ corrections for the final reaction products included.

Table S8. Fitting Parameters of Equation S1, Activation Energies and Reaction Enalthpies at $0 \mathrm{~K}$, and Entropies of Activation at $1000 \mathrm{~K}$ Obtained from Competitive Threshold Analyses for N-Glycosidic Bond Cleavage of O2 Protonated $[\mathrm{dCyd}+\mathrm{H}]^{+}$and $[\mathrm{Cyd}+\mathrm{H}]^{+a}$

\begin{tabular}{ccccccc}
\hline Reactant & Cross Section & $\mathrm{TS}$ & $\sigma_{0}{ }^{b}$ & $n^{b}$ & $\mathrm{E}_{0}(\mathrm{eV})$ & $\Delta \mathrm{S}^{+}{ }_{1000}\left(\mathrm{~J} \mathrm{~mol}^{-1} \mathrm{~K}^{-1}\right)$ \\
\hline$[\mathrm{dCyd}+\mathrm{H}]^{+}$ & {$[\mathrm{Cyt}+\mathrm{H}]^{+}$} & $\mathrm{TS}_{1}$ & $15.1(0.7)$ & $3.0(0.1)$ & $0.91(0.03)$ & $50(1)$ \\
& {$[\mathrm{dCyd}-\mathrm{Cyt}+\mathrm{H}]^{+}$} & $\mathrm{SW}$ & $3.2(3.1)$ & $3.0(0.1)$ & $1.49(0.04)$ & $108(4)$ \\
{$[\mathrm{dCyd}+\mathrm{H}]^{+}$} & {$[\mathrm{Cyt}+\mathrm{H}]^{+}$} & $\mathrm{TS}_{2}$ & $16.4(5.5)$ & $3.0(0.2)$ & $0.89(0.06)$ & $42(1)$ \\
& {$[\mathrm{dCyd}-\mathrm{Cyt}+\mathrm{H}]^{+}$} & $\mathrm{SW}$ & $1.9(1.2)$ & $3.0(0.2)$ & $1.51(0.08)$ & $108(4)$ \\
{$[\mathrm{Cyd}+\mathrm{H}]^{+}$} & {$[\mathrm{Cyt}+\mathrm{H}]^{+}$} & $\mathrm{TS}$ & $17.6(0.8)$ & $2.5(0.1)$ & $1.16(0.03)$ & $53(1)$ \\
& {$[\mathrm{Cyd}-\mathrm{Cyt}+\mathrm{H}]^{+}$} & $\mathrm{SW}$ & $1.0(0.2)$ & $2.5(0.1)$ & $1.82(0.06)$ & $111(4)$ \\
{$[\mathrm{Cyd}+\mathrm{H}]^{+}$} & {$[\mathrm{Cyt}+\mathrm{H}]^{+}$} & $\mathrm{TS}$ & $19.4(1.0)$ & $2.5(0.1)$ & $1.13(0.03)$ & $43(1)$ \\
& {$[\mathrm{Cyd}-\mathrm{Cyt}+\mathrm{H}]^{+}$} & $\mathrm{SW}$ & $0.6(0.2)$ & $2.5(0.1)$ & $1.85(0.05)$ & $111(4)$ \\
\hline
\end{tabular}

${ }^{a}$ Uncertainties are listed in parentheses. ${ }^{b}$ Average values for $\mathrm{TS}_{1}, \mathrm{TS}_{2}, \mathrm{TS}_{\mathrm{n}}$, and PSL associated with $\mathrm{N}$-glycosidic bond cleavage.

Table S9. Fitting Parameters of Equation S1, Activation Energies and Reaction Enalthpies at $0 \mathrm{~K}$, and Entropies of Activation at $1000 \mathrm{~K}$ Obtained from Competitive Threshold Analyses for N-Glycosidic Bond Cleavage of N3 Protonated $[\mathrm{dCyd}+\mathrm{H}]^{+}$and $[\mathrm{Cyd}+\mathrm{H}]^{+a}$

\begin{tabular}{ccccccc}
\hline Reactant & Cross Section & $\mathrm{TS}$ & $\sigma_{0}{ }^{b}$ & $n^{b}$ & $\mathrm{E}_{0}(\mathrm{eV})$ & $\Delta \mathrm{S}^{\dagger}{ }_{1000}\left(\mathrm{~J} \mathrm{~mol}^{-1} \mathrm{~K}^{-1}\right)$ \\
\hline$[\mathrm{dCyd}+\mathrm{H}]^{+}$ & {$[\mathrm{Cyt}+\mathrm{H}]^{+}$} & $\mathrm{TS}_{2}$ & $17.9(4.2)$ & $2.9(0.1)$ & $0.90(0.04)$ & $41(1)$ \\
& {$[\mathrm{dCyd}-\mathrm{Cyt}+\mathrm{H}]^{+}$} & $\mathrm{SW}$ & $3.3(3.1)$ & $2.9(0.1)$ & $1.56(0.05)$ & $108(4)$ \\
{$[\mathrm{Cyd}+\mathrm{H}]^{+}$} & {$[\mathrm{Cyt}+\mathrm{H}]^{+}$} & $\mathrm{TS}_{2}$ & $13.9(0.8)$ & $2.7(0.1)$ & $1.02(0.03)$ & $19(1)$ \\
& {$[\mathrm{Cyd}-\mathrm{Cyt}+\mathrm{H}]^{+}$} & $\mathrm{SW}$ & $2.0(0.6)$ & $2.7(0.1)$ & $1.93(0.05)$ & $111(4)$ \\
\hline
\end{tabular}

\footnotetext{
${ }^{a}$ Uncertainties are listed in parentheses. ${ }^{b}$ Average values for $\mathrm{TS}_{1}, \mathrm{TS}_{2}, \mathrm{TS}_{\mathrm{n}}$, and PSL associated with N-glycosidic bond cleavage.
} 
Table S10. Relative Energies $(\mathrm{kJ} / \mathrm{mol})$ Calculated for the Reactants, Transition States, Intermediates and Products for Producing $[\mathrm{Cyt}+\mathrm{H}]^{+}$from $\mathrm{O} 2$ Protonated $[\mathrm{dCyd}+\mathrm{H}]^{+}$and $[\mathrm{Cyd}+\mathrm{H}]^{+}$with a Polarizable Continuum Model.

\begin{tabular}{|c|c|c|c|c|c|c|c|}
\hline \multirow{2}{*}{ CID Channel } & & \multicolumn{2}{|c|}{ Relative Energies $^{a}$} & \multirow{2}{*}{ CID Channel } & & \multicolumn{2}{|c|}{ Relative Energies $^{a}$} \\
\hline & & B3LYP & MP2 & & & B3LYP & MP2 \\
\hline \multirow{6}{*}{$\begin{array}{c}\mathrm{Cyt}+\mathrm{H}]^{+} \text {from } \\
{[\mathrm{dCyd}+\mathrm{H}]^{+}}\end{array}$} & $\overline{\mathrm{TS}_{1}}$ & 85.5 & 123.6 & {$[\mathrm{Cyt}+\mathrm{H}]^{+}$from } & $\mathrm{TS}_{1}$ & 107.6 & 143.5 \\
\hline & $\mathrm{Int}_{1}$ & 83.8 & 121.8 & {$[\mathrm{Cyd}+\mathrm{H}]^{+}$} & $\mathrm{Int}_{1}$ & 106.8 & 143.0 \\
\hline & $\mathrm{TS}_{2}$ & 88.0 & 129.8 & & $\mathrm{TS}_{2}$ & 113.6 & 153.8 \\
\hline & $\mathrm{Int}_{2}$ & 27.6 & 64.5 & & $\mathrm{Int}_{2}$ & 17.2 & 54.2 \\
\hline & $\Delta \mathrm{H}_{\mathrm{rxn}}$ & 33.4 & 91.0 & & $\Delta H_{\mathrm{rxn}}$ & 30.4 & 94.8 \\
\hline & $\Delta \mathrm{H}_{\mathrm{rxn}} b$ & 26.9 & 45.0 & & $\Delta \mathrm{H}_{\mathrm{rxn}}{ }^{b}$ & 23.2 & 45.8 \\
\hline
\end{tabular}

${ }^{a} \mathrm{~B} 3 \mathrm{LYP} / 6-311+\mathrm{G}(2 \mathrm{~d}, 2 \mathrm{p})$ and MP2/6-311+G(2d,2p) relative energies of B3LYP/6-311+G(d,p) optimized structures at $0 \mathrm{~K}$ including ZPE corrections with frequencies scaled by $0.99 .{ }^{b} \mathrm{BSSE}$ corrections are included for the final reaction products.

Table S11. Relative Energies (kJ/mol) Calculated for the Reactants, Transition States, Intermediates and Products for Producing $[\mathrm{Cyt}+\mathrm{H}]^{+}$from N3 Protonated $[\mathrm{dCyd}+\mathrm{H}]^{+}$and $[\mathrm{Cyd}+\mathrm{H}]^{+}$with a Polarizable Continuum Model.

\begin{tabular}{|c|c|c|c|c|c|c|c|}
\hline \multirow{2}{*}{ CID Channel } & & \multicolumn{2}{|c|}{ Relative Energies $^{a}$} & \multirow{2}{*}{ CID Channel } & & \multicolumn{2}{|c|}{ Relative Energies $^{a}$} \\
\hline & & B3LYP & MP2 & & & B3LYP & MP2 \\
\hline \multirow{6}{*}{$\begin{array}{c}{[\mathrm{Cyt}+\mathrm{H}]^{+} \text {from }} \\
{[\mathrm{dCyd}+\mathrm{H}]^{+}}\end{array}$} & $\mathrm{TS}_{1}$ & 98.1 & 141.5 & \multirow{6}{*}{$\begin{array}{c}{[\mathrm{Cyt}+\mathrm{H}]^{+} \text {from }} \\
{[\mathrm{Cyd}+\mathrm{H}]^{+}}\end{array}$} & $\mathrm{TS}_{1}$ & 97.6 & 142.8 \\
\hline & $\mathrm{Int}_{1}$ & 56.4 & 76.5 & & Int $_{1}$ & 93.4 & 140.0 \\
\hline & $\mathrm{TS}_{2}$ & 101.7 & 142.3 & & $\mathrm{TS}_{2}$ & 103.0 & 147.5 \\
\hline & $\mathrm{Int}_{2}$ & 30.7 & 67.3 & & $\mathrm{Int}_{2}$ & 23.3 & 54.7 \\
\hline & $\Delta \mathrm{H}_{\mathrm{rxn}}$ & 34.7 & 90.9 & & $\Delta \mathrm{H}_{\mathrm{rxn}}$ & 41.0 & 103.4 \\
\hline & $\Delta \mathrm{H}_{\mathrm{rxn}}{ }^{b}$ & 28.4 & 45.5 & & $\Delta \mathrm{H}_{\mathrm{rxn}}{ }^{b}$ & 34.0 & 54.4 \\
\hline
\end{tabular}

${ }^{a} \mathrm{~B} 3 \mathrm{LYP} / 6-311+\mathrm{G}(2 \mathrm{~d}, 2 \mathrm{p})$ and $\mathrm{MP} 2 / 6-311+\mathrm{G}(2 \mathrm{~d}, 2 \mathrm{p})$ relative energies of B3LYP/6-311+G(d,p) optimized structures at $0 \mathrm{~K}$ including ZPE corrections with frequencies scaled by $0.99 .{ }^{b} \mathrm{BSSE}$ corrections are included for the final reaction products.

Table S12. Enthalpies and Free Energies for N-Glycosidic Bond Cleavage of $[\mathrm{dCyd}+\mathrm{H}]^{+}$and $[\mathrm{Cyd}+\mathrm{H}]^{+}$at 0 and 298 $\mathrm{K}$ in kJ/mol. ${ }^{a}$

\begin{tabular}{cccccccccc}
\hline Reactant & CID Product & $\Delta H_{0}$ & $\Delta H_{0}{ }^{b}$ & $\Delta H_{298}-\Delta H_{0}{ }^{b}$ & $\Delta H_{298}$ & $\Delta H_{298}{ }^{b}$ & $T \Delta S_{298}{ }^{b}$ & $\Delta G_{298}$ & $\Delta \mathrm{G}_{298}{ }^{b}$ \\
\hline$[\mathrm{dCyd}+\mathrm{H}]^{+}$ & {$[\mathrm{Cyt}+\mathrm{H}]^{+}$} & $85.9(5.8)$ & 83.8 & $5.3(0.5)$ & $91.2(5.8)$ & 89.1 & $11.5(3.4)$ & $79.7(6.7)$ & 77.6 \\
& {$[\mathrm{dCyd}-\mathrm{Cyt}+\mathrm{H}]^{+}$} & $145.7(7.7)$ & 147.5 & $2.0(0.7)$ & $147.7(7.7)$ & 149.5 & $56.4(2.9)$ & $91.3(8.3)$ & 93.1 \\
{$[\mathrm{Cyd}+\mathrm{H}]^{+}$} & {$[\mathrm{Cyt}+\mathrm{H}]^{+}$} & $111.9(2.9)$ & 111.3 & $5.9(0.8)$ & $117.8(3.0)$ & 117.2 & $15.7(5.0)$ & $102.2(5.8)$ & 101.6 \\
& {$[\mathrm{Cyd}-\mathrm{Cyt}+\mathrm{H}]^{+}$} & $175.6(5.8)$ & 171.2 & $2.0(0.7)$ & $177.6(5.8)$ & 173.2 & $57.6(5.3)$ & $120.0(7.9)$ & 115.6 \\
\hline
\end{tabular}

${ }^{a}$ Present results, uncertainties are listed in parenthese. ${ }^{b}$ Values from the theoretical calculations at the B3LYP/6$311+\mathrm{G}(2 \mathrm{~d}, 2 \mathrm{p})$ level of theory using the B3LYP/6-311+G(d,p) optimized geometries. 
Figure S1.

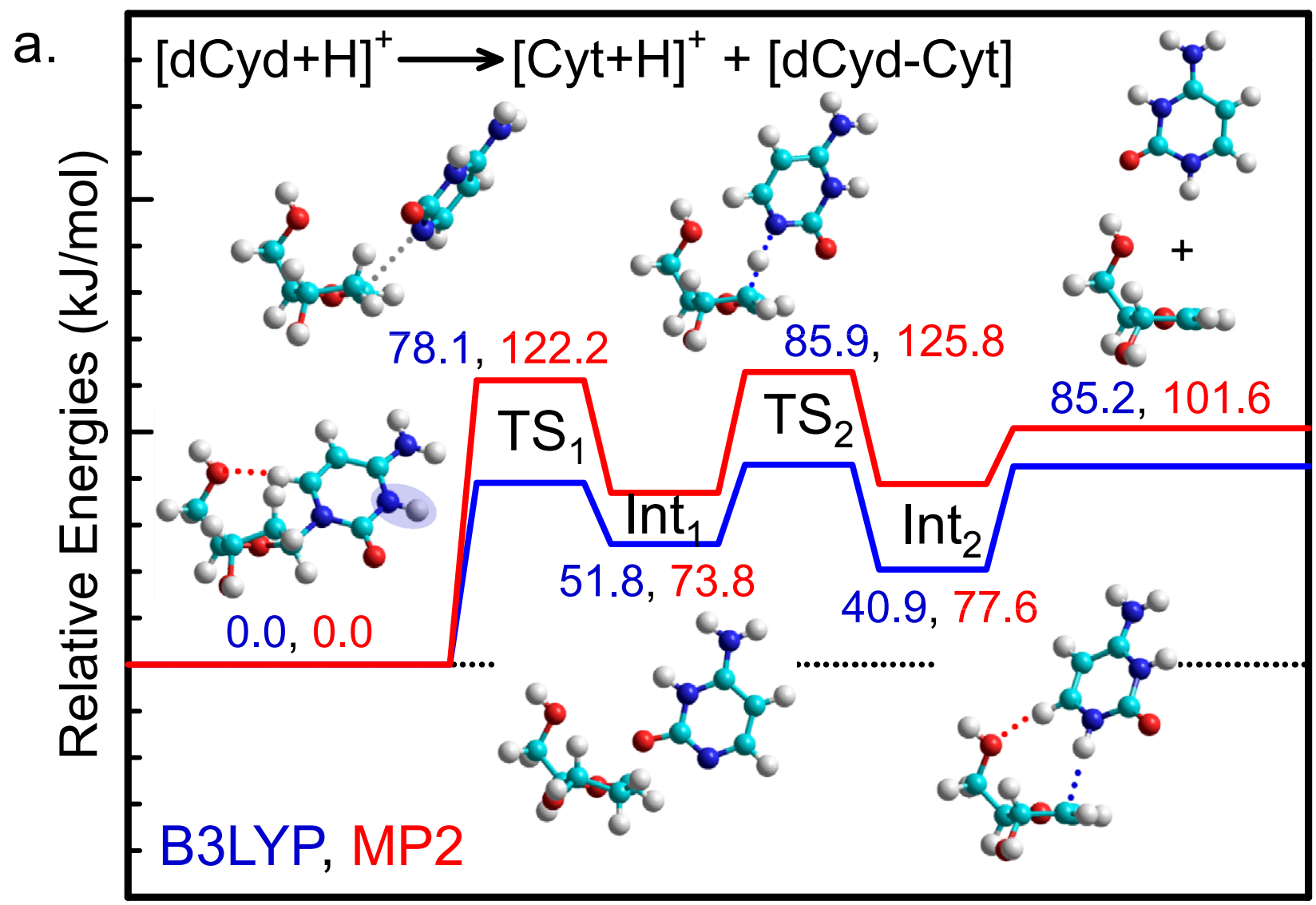

Reaction Coordinate

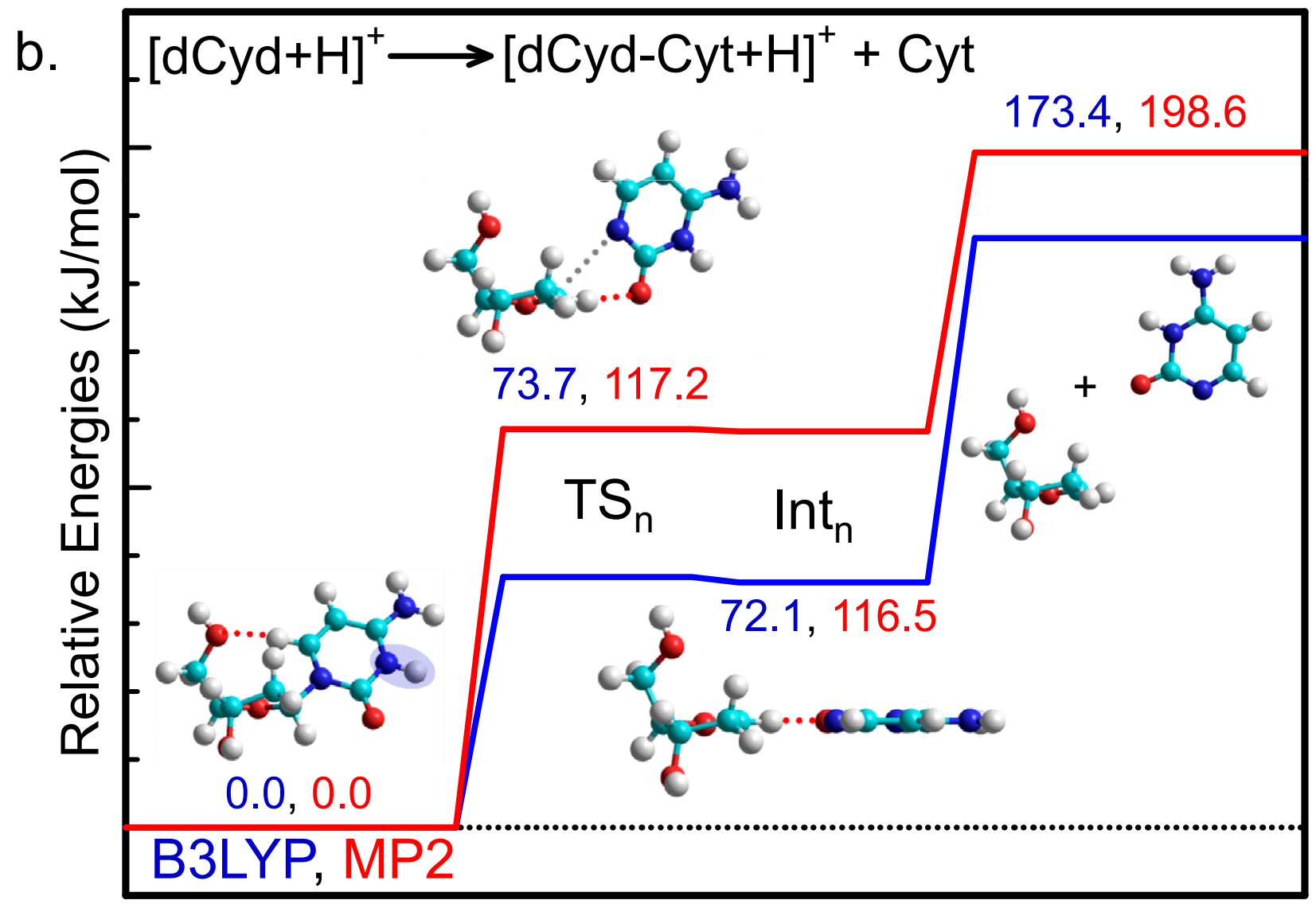

Reaction Coordinate 
Figure S2.

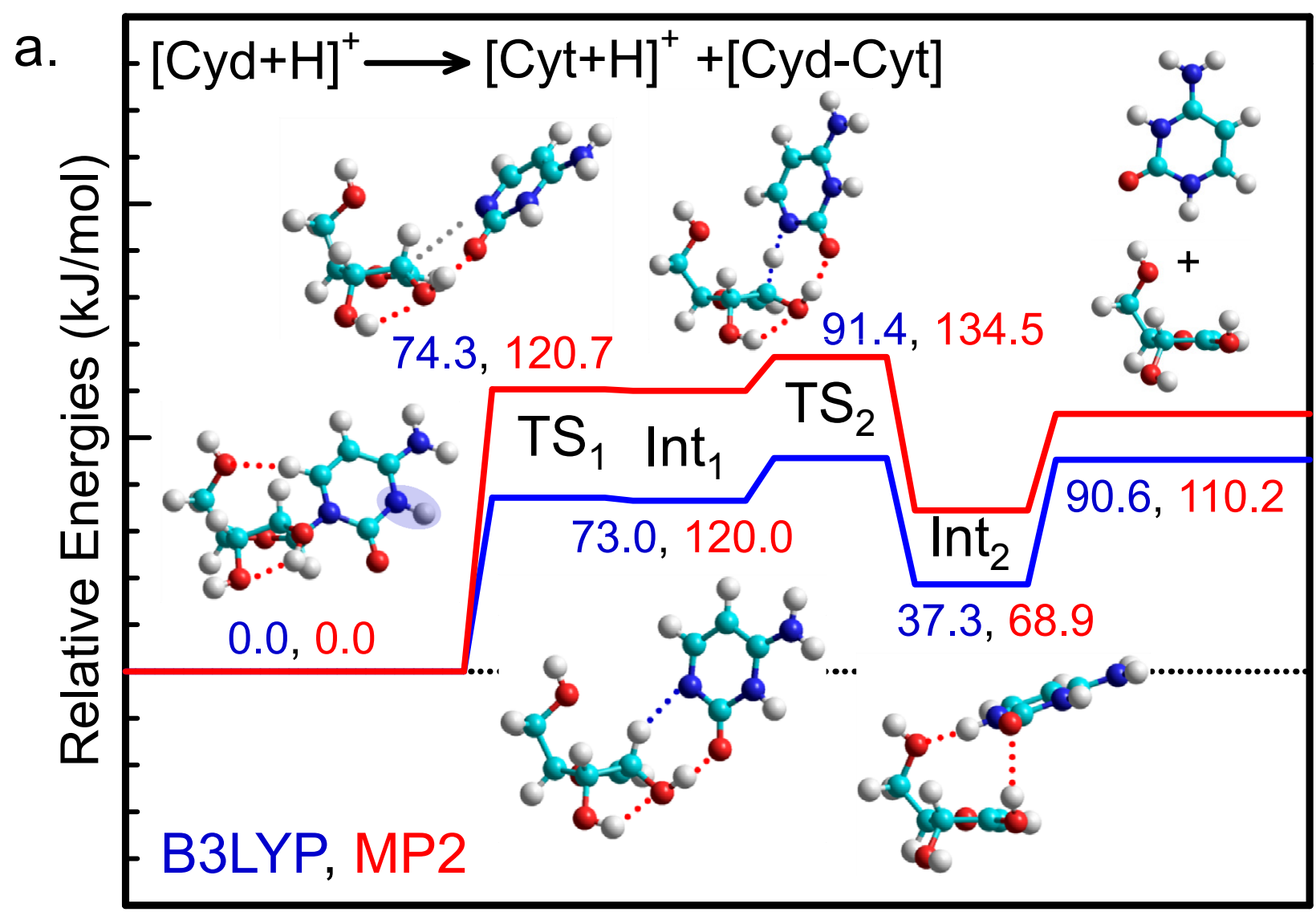

Reaction Coordinate

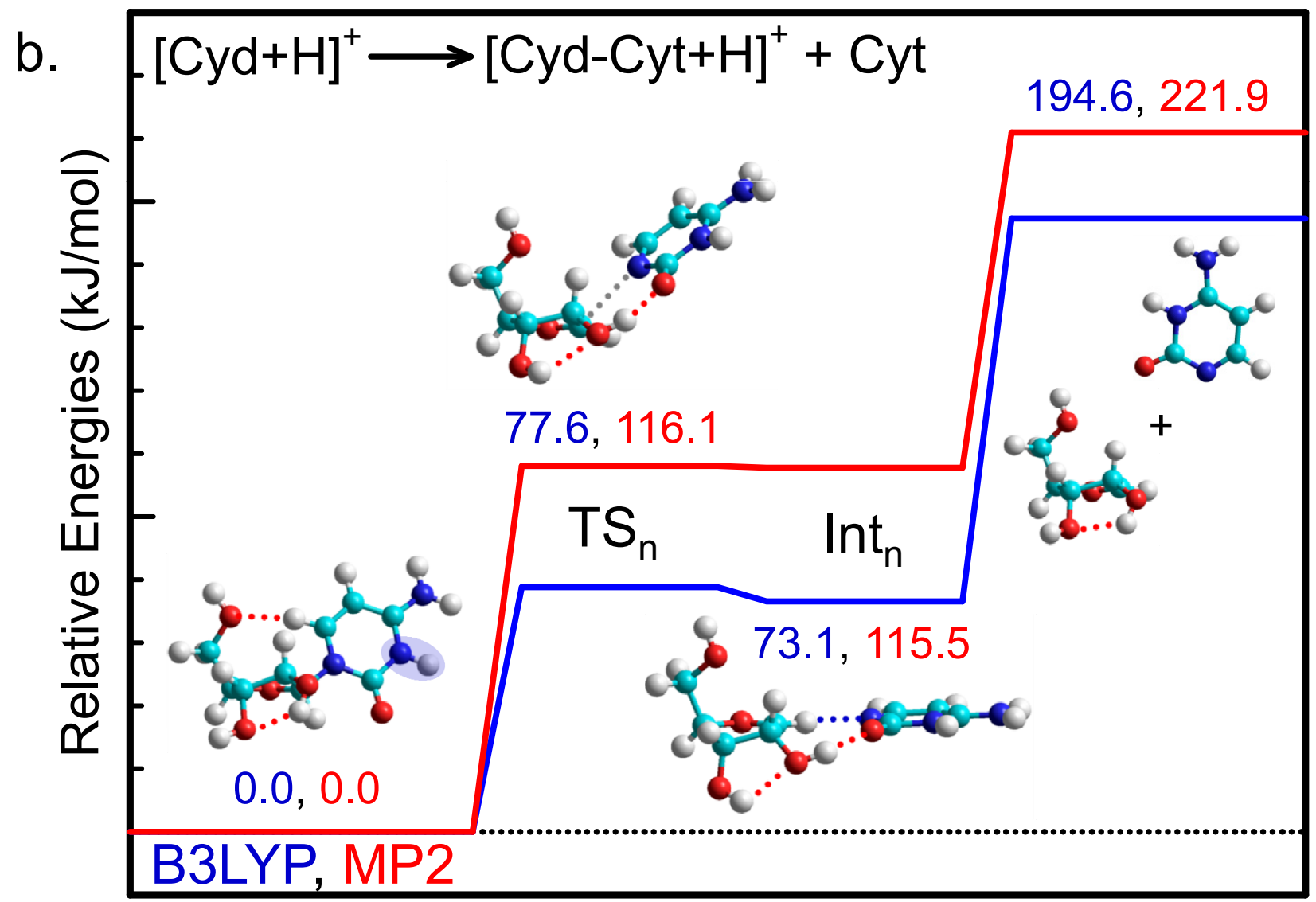

Reaction Coordinate 